\title{
Chiral-Electroactive Low-Bandgap Polymer Composite
}

\author{
Naoto Eguchi, Kohsuke Kawabata, Hiromasa Goto* \\ Faculty of Pure and Applied Sciences, Division of Material Sciences, University of Tsukuba, Tsukuba, Japan \\ Email: ^gotoh@ims.tsukuba.ac.jp
}

How to cite this paper: Eguchi, N., Kawabata, K. and Goto, H. (2017) Chiral-Electroactive Low-Bandgap Polymer Composite. Journal of Materials Science and Chemical Engineering, 5, 1-10.

https://doi.org/10.4236/msce.2017.52001

Received: December 28, 2016

Accepted: February 5, 2017

Published: February 8, 2017

Copyright $\odot 2017$ by authors and Scientific Research Publishing Inc. This work is licensed under the Creative Commons Attribution International License (CC BY 4.0).

http://creativecommons.org/licenses/by/4.0/ (c) (i) Open Access

\begin{abstract}
Electrochemical polymerization of an isothianaphthene based monomer for low-bandgap polymer was carried out in a polymer lyotropic liquid crystal. We prepared hydroxypropyl cellulose/ $N, N$-dimethylformamide (HPC/DMF) lyotropic liquid crystal system as an electrolyte solution to perform electrochemical polymerization of a hydrophobic monomer, although water was commonly employed as a solvent for HPC. Resultant polymer prepared in HPC/DMF shows both electro-activity and optical activity. Fourier transform infrared absorption spectroscopy measurement reveals that the resultant material is composite of HPC and polyisothianaphthene based.
\end{abstract}

\section{Keywords}

Electrochemical Polymerization, Conjugated Polymer, Isothianaphthene, Hydroxypropyl Cellulose, Composite

\section{Introduction}

Isothianaphthene is one of the most studied polymers among conductive polymers. The synthesis requires high experimental technique of ring closure reaction with suppression of side reaction of polymerization [1]-[17]. Protection of $\alpha$-positon of the thiophene ring of the isothianaphthene unit with silyl group has been carried out. Vanderzande group synthesized an isothianaphthene sandwiched monomer between thiophene units for improving stability, and carried out electrochemical polymerization [5] [8]. Resultant polymer shows low-bandgap nature derived from isothianaphthene, and shows good redox property. Isothianaphthene based polymer also displays good electrochromic property [18] [19] [20]. While crystallinity of electrochemically synthesized polymers prepared in common organic solvent is high, control of morphology of main-chain structure is difficult. To date, we have carried out electrochemical polymerization in lowmolecular-mass liquid crystal as an electrolyte solution. The polymer thus 
obtained reflects structure of liquid crystal electrolyte solution from molecular level to macroscopic level. However, a large quantity of liquid crystals needs to be applied for reaction medium. Further, multi-step synthesis is required for obtaining low molecular liquid crystals. Although reuse of the liquid crystal electrolyte solution is possible, purification is required. Hydroxypropyl cellulose (HPC) is a semi-natural polymer by modification with the propyl group [21] [22] [23] [24]. Hydroxypropyl cellulose (HPC) is an amphotropic polymer and acts as surfactant. Recently, HPC is used as a template or composite material [25] [26] [27]. HPC dissolves in both water and organic systems. Furthermore, HPC exhibits lyotropic liquid crystallinity in the water or organic solvent at appropriate concentration. To perform electrochemical polymerization in liquid crystal, monomer needs to be dissolved in the liquid crystal electrolyte solution. Many monomers are soluble only in organic solvents and have hydrophobic property. So, electrochemical polymerization of hydrophobic monomers needs to perform in organic solvent. HPC/organic liquid crystal medium can overcome this point. High concentrated HPC in DMF solution shows lyotropic liquid crystallinity, and hydrophobic organic monomers can dissolve in the HPC/DMF system. So, organic monomer can polymerize in the HPC/DMF. Moreover, HPC shows cholesteric liquid crystal having an optically activity with helical structure in organic solvents. The polymer prepared in this system is expected to be chiral polymer. Based on this consideration, we electrochemically synthesize an isothianaphthene based optically active low-bandgap polymer in HPC/DMF electrolyte solution.

\section{Experimental}

\subsection{Materials}

A monomer [thiophene]-[isothianaphthene]-[thiophene] was prepared by previously reported method [3]. Hydroxypropyl cellulose was obtained from Wako Pure Chemical Industries, Ltd. and used as supplied. Tetrabutylammonium perchlorate was obtained from Tokyo Chemical Industry Co., Ltd. and used as supplied. $N, N$-dimethylformamide was obtained from Nacalai Tesque, Inc. and used as supplied.

\subsection{Electrochemical Polymerization}

Electrochemical polymerization of a monomer [thiophene]-[isothianaphthene][thiophene], abbreviated as T-ITN-T, was carried out in hydroxypropyl cellulose (Figure 1). Constituents of electrolyte solution are summarized in Table 1. Firstly, tetrabutylammonium perchlorate (TBAP) (supporting salt) and monomer was dissolved in $\mathrm{N}, \mathrm{N}$-dimethylforma- mide (DMF) (Figure 2(a)). Next, hydroxypropyl cellulose was added to the electrolyte solution containing monomer and supporting salt (Figure 2(b)). The solution was stirred mechanically by glass rod for $1 \mathrm{~min}$ at room temperature (Figure 2(c)). A polarizing optical microscopy image of the lyotropic liquid crystal solution is shown in Figure 3. Then, electrochemical polymerization was carried out by using sandwich cell 

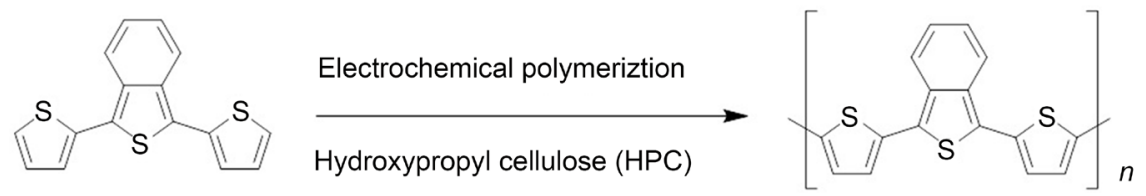

Figure 1. Scheme of electrochemical polymerization of [thiophene]-[isothianaphthene][thiophene].

Table 1. Constituents of electrolyte solution.

\begin{tabular}{cccc}
\hline & Matrix & Solvent & Supporting salt \\
\cline { 2 - 4 } Monomer & $\mathrm{HPC}^{\mathrm{b}}$ & $\begin{array}{c}N, N \text {-dimethylformamide } \\
(\mathrm{DMF})\end{array}$ & $\begin{array}{c}\left(\mathrm{C}_{4} \mathrm{H}_{9}\right)_{4} \mathrm{~N}^{+} \mathrm{ClO}_{4}^{-} \\
\left(\mathrm{TBAP}^{\mathrm{c}}\right)\end{array}$ \\
\hline
\end{tabular}

${ }^{\mathrm{a}}$ [thiophene]-[isothianaphthene]-[thiophene]; ${ }^{\mathrm{b}} \mathrm{Hydroxypropyl}$ cellulose; ${ }^{\mathrm{c}}$ Tetrabutylammonium perchlorate.

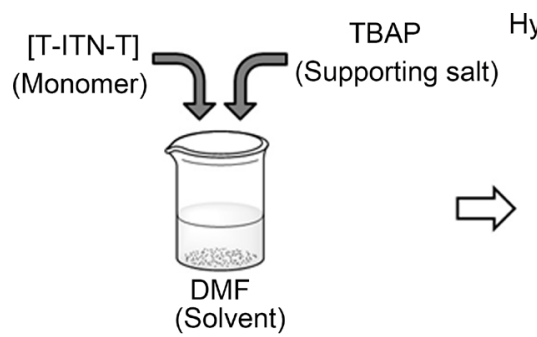

(a)

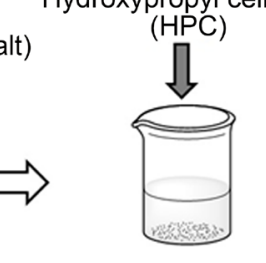

(b)

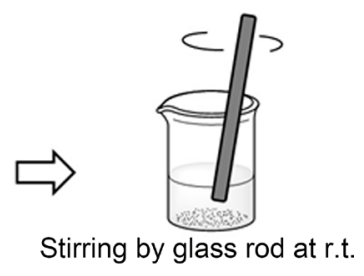

(c)

Figure 2. Experimental diagram for preparation of electrolyte solution containing monomer.

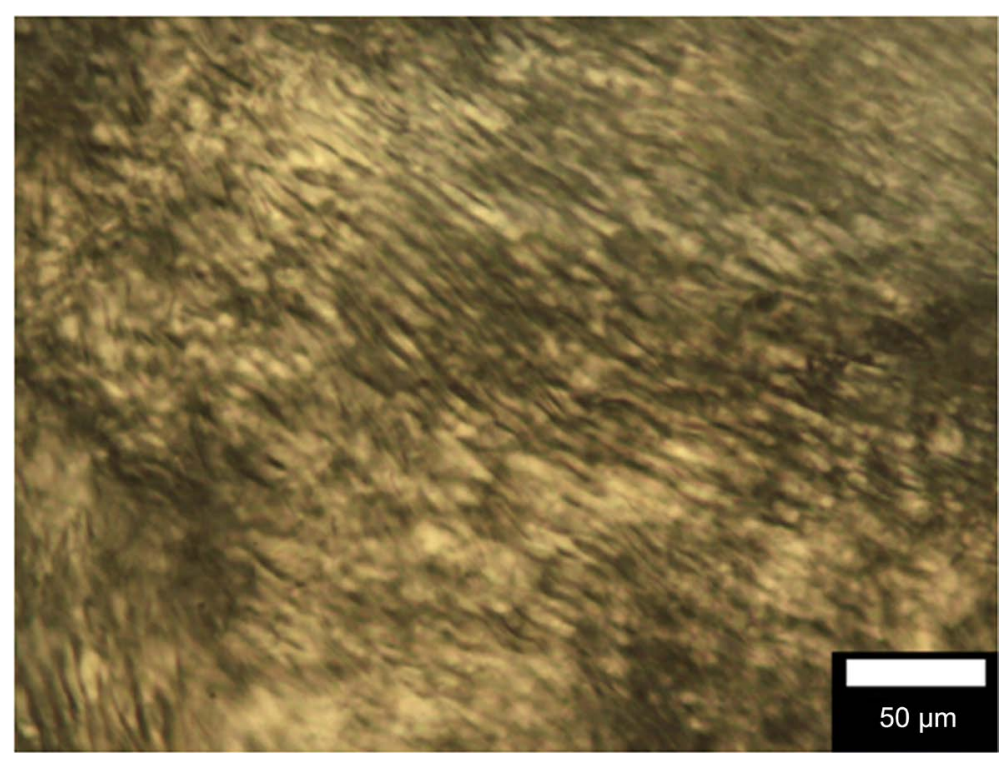

Figure 3. Polarizing optical microscopy image of electrolyte solution. 
method with two ITO glass electrodes (ITO = indium tin oxide) developed by our group previously. Direct current $(\mathrm{dc})$ voltage of $2.5 \mathrm{~V}$ was applied across of the cell for $60 \mathrm{~min}$. A thin film was deposited on an anode side of the electrode. After the electrochemical reaction, the sandwich cell was soaked into the water to remove the residual HPC from the film surface. After a $30 \mathrm{~min}$, the sandwich cell was disassembled easily. The resultant was washed with water, and acetone to yield a thin film deposited on the ITO coated glass, abbreviated as $\mathrm{P}(\mathrm{T}-\mathrm{ITN}-\mathrm{T}) / \mathrm{HPC}$.

\subsection{Measurements}

Optical texture observations were carried out by using an ECLIPS LV 100 highresolution polarizing microscope (Nikon). Fourier Transform Infrared absorption was obtained with a FT-IR 4600 (Jasco) by using the KBr method. UV-vis absorption spectroscopy was carried out by using V-630 (Jasco). Cyclic voltammetory were carried out with a $\mu$ AUTOLAB TYPE III (ECO Chemie). Electrolyte solution contained 0.1 M TBAP in acetonitrile. Circular dichroism spectroscopy was carried out with a J-720 (Jasco).

\section{Results and Discussion}

\subsection{Polarizing Optical Microscopy Observation}

The polymer thus obtained shows clear fingerprint texture under polarizing optical microscopy (POM) in Figure 4. The fingerprint pattern is derived from cholesteric liquid crystal of HPC helical aggregation, indicating occurrence of transcription of helical structure of HPC during the electrochemical polymerization. In this case, HPC acts as a helical template.

\subsection{Fourier Transform Infrared Absorption}

Fourier transform infrared (FT-IR) absorption spectroscopy measurements of

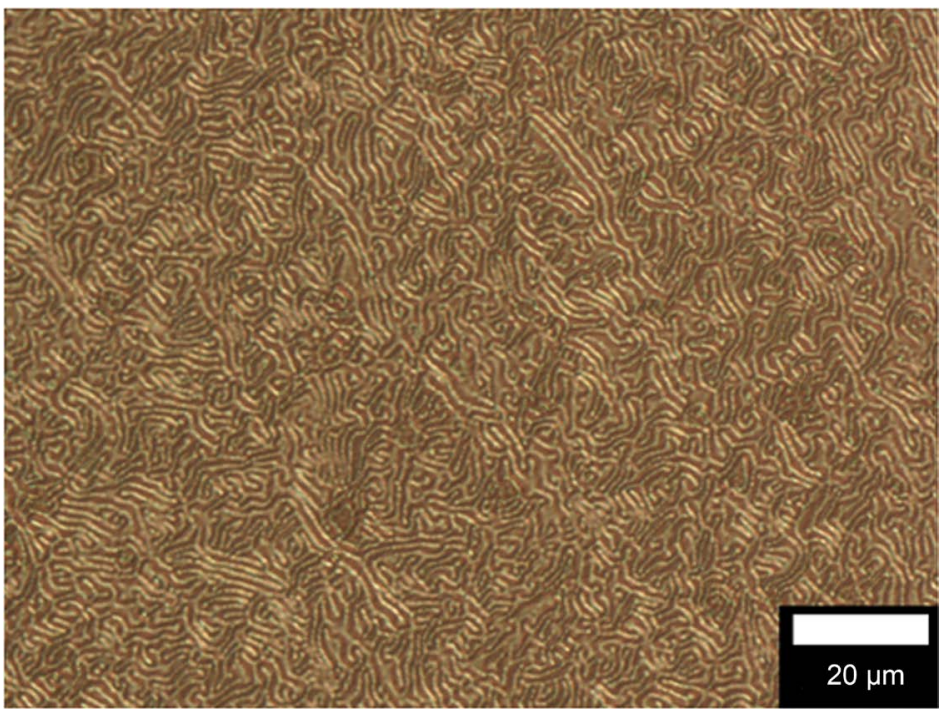

Figure 4. Polarizing optical microscopy (POM) image of obtained polymer film. 
HPC (matrix), T-ITN-T (monomer) and P(T-ITN-T)/HPC are shown in Figure 5. HPC shows broad $\mathrm{O}-\mathrm{H}$ vibration absorption around $3450 \mathrm{~cm}^{-1}$ due to hydroxyl group in the pyranose unit. Absorption band around $2960 \mathrm{~cm}^{-1}$ is due to $\mathrm{CH}_{2}$ and $\mathrm{CH}$ stretching vibration. The polymer shows absorption band at 3430 $\mathrm{cm}^{-1}$ due to the $\mathrm{O}-\mathrm{H}$ stretching vibration of cellulose unis. This result revealed that the resultant material is composite of P(T-ITN-T) and HPC. HPC component cannot be separated after washing of the film with solvents.

\subsection{UV-Vis Absorption}

In situ UV-vis absorption measurements were carried out during cyclic voltammetry measurement. Change in the UV-vis of $\mathrm{P}(\mathrm{T}-\mathrm{ITN}-\mathrm{T}) / \mathrm{HPC}$ at various application potential are shown in Figure 6. The polymer shows absorption band at around $550 \mathrm{~nm}$ due to $\pi-\pi^{*}$ transition of main chain. A new absorption band at $960 \mathrm{~nm}$ is derived from polaron band (radical cation) at oxidation process (Figure 6(a)). The absorption intensity of polaron band increases with application of voltages, indicating progress of electrochemical oxidation (doping). On the other hands, reduction process (Figure 6(b)) shows decrease of absorption intensity of the polaron band. The electrochemically reduced state at $0 \mathrm{~V}$ of the composite has a bandgap of $1.5 \mathrm{eV}$, which is in the range of low-bandgap conjugated polymers.

Changes in intensity of absorptions are repeatable through electrochemical doping/dedopoing (redox) process. To confirm the repeatable electrochromic property, change in absorption intensity at 550, 730 and $1030 \mathrm{~nm}$ upon repeating application of voltage between 0 and $1.0 \mathrm{~V}$ (vs. $\mathrm{Ag} / \mathrm{Ag}^{+}$) was examined for $750 \mathrm{~s}$

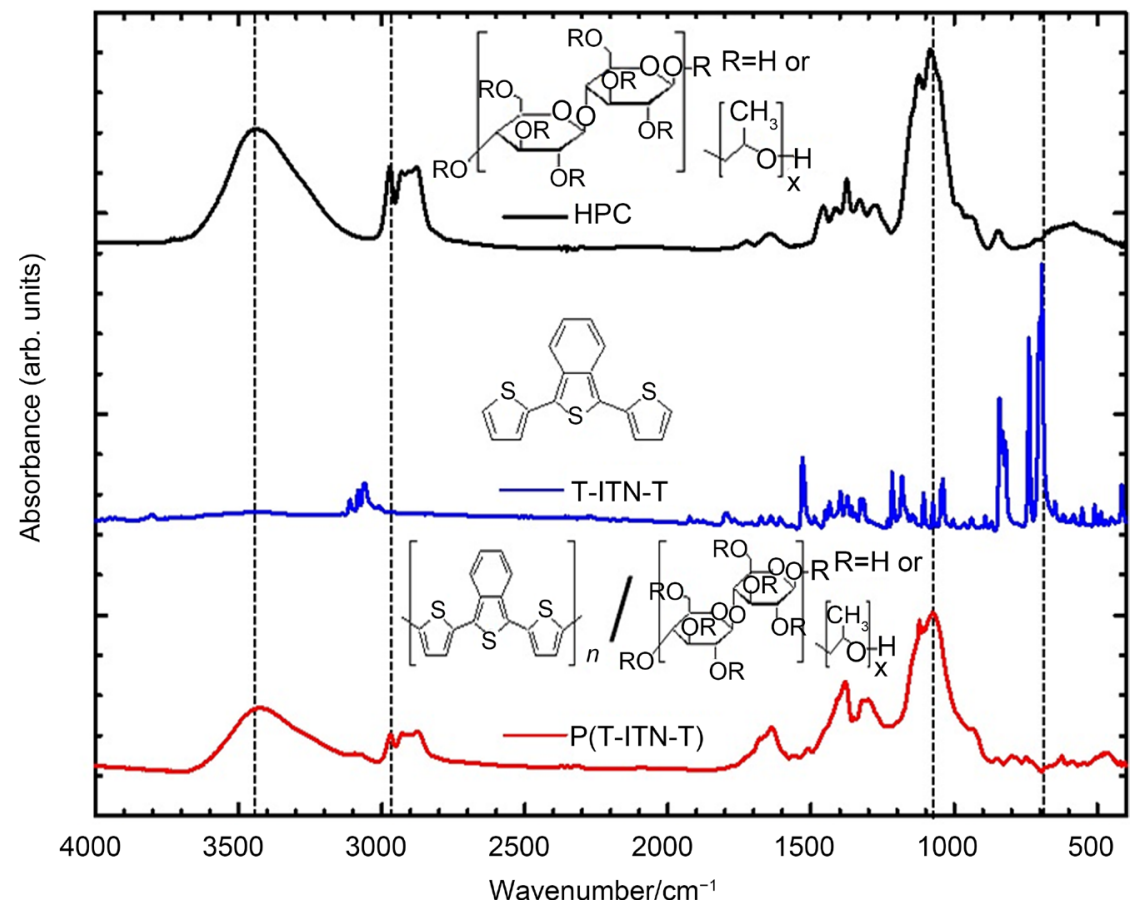

Figure 5. FT-IR spectra of hydroxypropyl cellulose (HPC) (black line), monomer (T-ITN-T) (blue line) and P(T-ITN-T)/HPC (red line). 

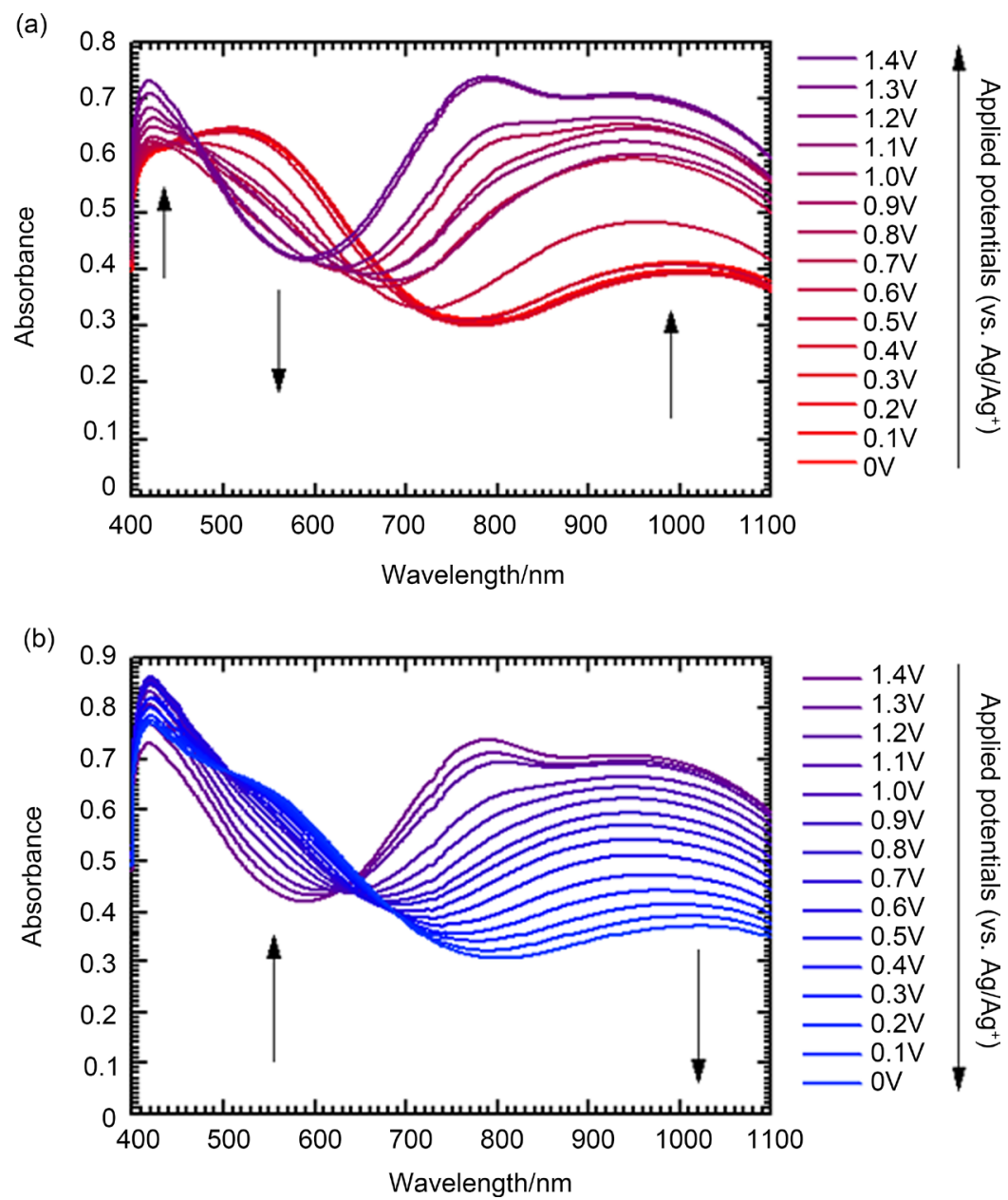

Figure 6. UV-vis absorption spectra of $\mathrm{P}(\mathrm{T}-\mathrm{ITN}-\mathrm{T}$ ) at various applied potentials (vs. $\mathrm{Ag} / \mathrm{Ag}^{+}$). Oxidation process (a) and reduction process (b).

at a scan rate of $50 \mathrm{mV} / \mathrm{s}$ (Figure 7).

\subsection{Cyclic Voltammetry}

Cyclic voltammetry (CV) analysis of $\mathrm{P}(\mathrm{T}-\mathrm{ITN}-\mathrm{T}) / \mathrm{HPC}$ was carried out at various scan rates of $10,20,30,40,50,60,70,80,90$ and $100 \mathrm{mV} / \mathrm{s}$. The CV result is shown in Figure 8. First oxidation wave indicates that the polymer film was oxidized and polarons (radical and cation) were generated. At reduction process, reduced wave was confirmed, indicating that the polymer film was reduced. The polymer film exhibits repeatable redox behavior in the applied potential range from 0 to $1.0 \mathrm{~V}$ (vs. $\mathrm{Ag} / \mathrm{Ag}^{+}$).

\subsection{Circular Dichroism Absorption}

Circular dichroism (CD) absorption spectroscopy measurement was carried out for as prepared polymer film and reduced polymer film. The CD spectra of the film are shown in Figure 9. The reduced film was prepared by hydrazine vapor for $30 \mathrm{~min}$. Reduction allows increase of the absorption band at around $400 \mathrm{~nm}$ due to decrease of fraction of polarons in the main-chain accompanied by 


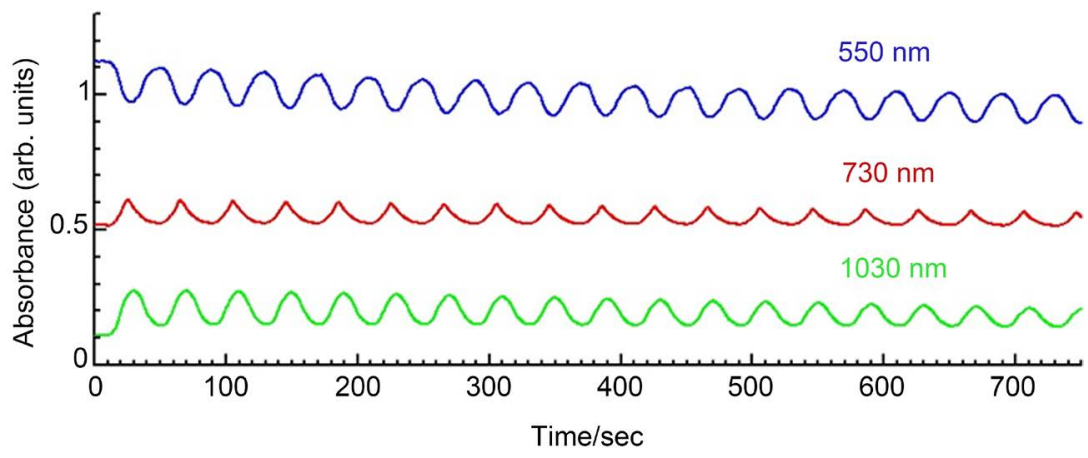

Figure 7. Time dependence of the UV-vis absorption intensity at 550, 730 and $1030 \mathrm{~nm}$ of $\mathrm{P}(\mathrm{T}-\mathrm{ITN}-\mathrm{T}) / \mathrm{HPC}$ film during repeated potential cycled between 0 and $1.0 \mathrm{~V}$ (vs. $\mathrm{Ag} / \mathrm{Ag}^{+}$) for $750 \mathrm{~s}$ at a scan rate of $50 \mathrm{mV} / \mathrm{s}$.

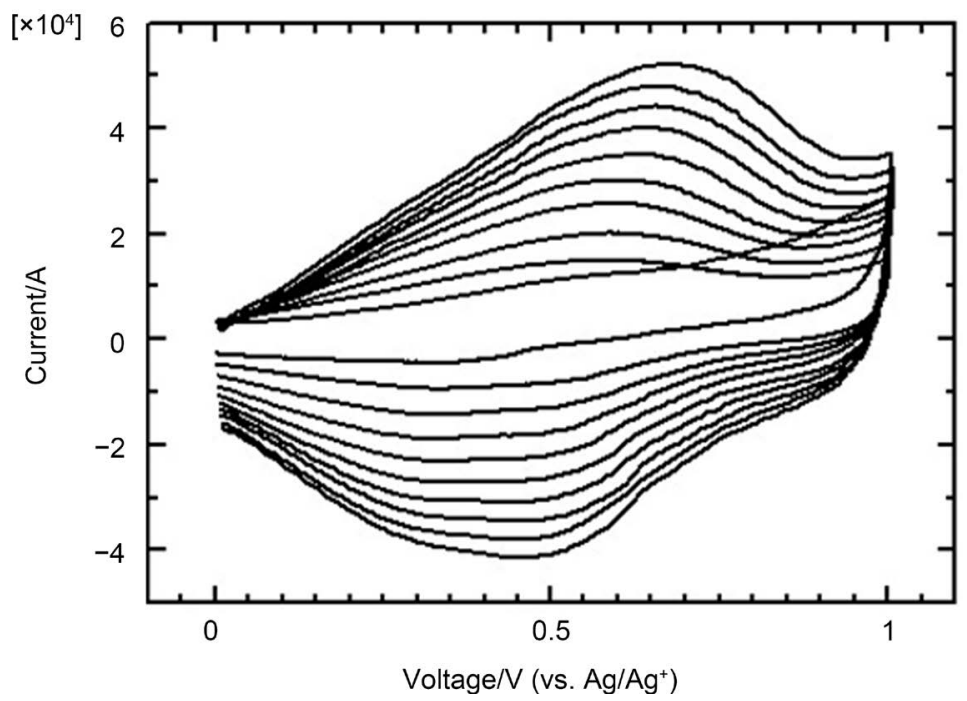

Figure 8. Cyclic voltammogram of $\mathrm{P}(\mathrm{T}-\mathrm{ITN}-\mathrm{T}) / \mathrm{HPC}$ at various scan rates of $10,20,30$, $40,50,60,70,80,90$, and $100 \mathrm{mV} / \mathrm{s}$ vs. $\mathrm{Ag} / \mathrm{Ag}^{+}$reference electrode in $0.1 \mathrm{M} / \mathrm{TBAP}$ acetonitrile solution. TBAP $=$ tetrabutylammonium perchlorate.

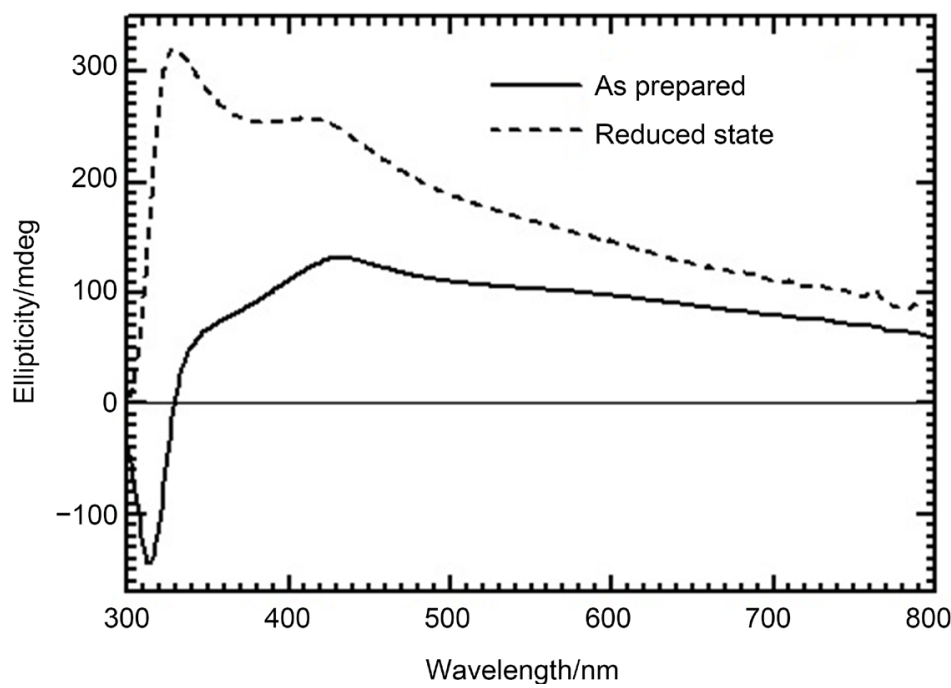

Figure 9. CD spectra of $\mathrm{P}(\mathrm{T}-\mathrm{ITN}-\mathrm{T})$. As prepared state (solid line) and reduced state (dashed line). 
de-doping, indicating optical activity of the composite can be changed by the reduction.

\section{Conclusion}

Synthesis of a P(T-ITN-T)/HPC composite film by electrochemical polymerization in a HPC liquid crystal medium was successfully carried out. The POM observation for the composite film shows a fingerprint texture resembling the cholesteric liquid crystal and indicates that transcription of a helical structure of HPC is occurred. In situ UV-vis absorption spectra and cyclic voltammetry show that the polymer has repeatable electrochromic property. The CD spectroscopy measurements suggest that synthesis of the optical active composite is achieved from a monomer having no asymmetric carbon. The optical bandgap of P(T-ITNT)/HPC is estimated to be $1.5 \mathrm{eV}$, which is in the range of low-bandgap conjugated polymers.

\section{Acknowledgements}

We would like to thank Tsukuba Research Center for Interdisciplinary Materials Science (TIMS).

\section{References}

[1] Lorcy, D. and Cava, M.P. (1992) Poly(Isothianaphthene-Bithiophefe): A New Regularly Structured Polythiophene Analogue. Advanced Materials, 4, 562-564. https://doi.org/10.1002/adma.19920040906

[2] Bäuerle, P., Götz, G., Emerle, P. and Port, H. (1992) Synthesis and Characterization of New Annelated Terheterocycles. Advanced Materials, 4, 564-568. https://doi.org/10.1002/adma.19920040907

[3] Hoogmartens, I., Adriaensens, P., Carleer, R., Vanderzande, D., Martens, H. and Gelan, J. (1992) An Investigation into the Electronic Structure of Poly(Isothianaphthene). Synthetic Metals, 51, 219-228. https://doi.org/10.1016/0379-6779(92)90274-M

[4] Musmanni, S. and Ferraris, J.P. (1993) Preparation and Characterization of Conducting Polymers Based on 1,3-Di(2-Thienyl)Benzo [c] Thiophene. Journal of the Chemical Society, Chemical Communications, No. 2, 172-174. https://doi.org/10.1039/c39930000172

[5] Kiebooms, R., Hoogmartens, I., Adriaensens, P., Vanderzande, D. and Gelan, J. (1995) Low-Band-Gap Conjugated Polymers. Improved Model Compounds for the Structural Analysis of Poly(Isothianaphthene). Macromolecules, 28, 4961-4969. https://doi.org/10.1021/ma00118a025

[6] Kiebooms, R.H., Adriaensens, P.J., Vanderzande, D.J. and Gelan, J.M. (1997) Grignard Reactions on Ortho Dicarboxylic Arene Derivatives. Synthesis of 1,3-Dithienylisothianaphthene Compounds. The Journal of Organic Chemistry, 62, 1473-1480. https://doi.org/10.1021/jo9604402

[7] Mohanakrishnan, A.K., Lakshmikantham, M.V., McDougal, C., Cava, M.P., Baldwin, J.W. and Metzger, R.M. (1998) Studies in the Dithienylbenzo [c] Thiophene Series. The Journal of Organic Chemistry, 63, 3105-3112. https://doi.org/10.1021/jo980246a

[8] Lapkowski, M., Kiebooms, R., Gelan, J., Vanderzande, D., Pron, A., Louarn, G. and 
Lefrant, S. (1999) Spectroelectrochemical Behaviour of Poly (2, 5-Dithienylene-Isothianaphthene) and Its Analogue Deuterated on the Benzene Ring.

[9] Hughes, T.V. and Cava, M.P. (1999) Electrophilic Cyanations Using 1-Cyanobenzotriazole: $\mathrm{sp}^{2}$ and sp Carbanions. The Journal of Organic Chemistry, 64, 313-315. https://doi.org/10.1021/jo981924w

[10] Mitschke, U. and Bäuerle, P. (2001) Synthesis, Characterization, and Electrogenerated Chemiluminescence of Phenyl-Substituted, Phenyl-Annulated, and Spirofluorenyl-Bridged Oligothiophenes. Journal of the Chemical Society, Perkin Transactions 1, 740-753. https://doi.org/10.1039/b006553f

[11] Kool, E.T. (2002) Fluorescent Nucleoside Analogs and Combinatorial Fluorophore Arrays Comprising Same. US Patent No. 6479650.

[12] Kisselev, R. and Thelakkat, M. (2002) Synthesis of Novel 1,3-Bis (5-Diarylaminothiophen-2-yl)Isothianaphthenes. Chemical Communications, 14, 1530-1531. https://doi.org/10.1039/b202943j

[13] Kisselev, R. (2004) Synthesis, Characterisation and Application of Low Molecular Weight and Polymeric 1,3-Di-2-Thienylbenzo [c] Thiophenes. Ph.D. Thesis, Bayreuth University, Bayreuth.

[14] Kisselev, R. and Thelakkat, M. (2004) Synthesis and Characterization of Poly(Triarylamine)s Containing Isothianaphthene Moieties. Macromolecules, 37, 8951-8958. https://doi.org/10.1021/ma0495947

[15] Amaladass, P., Clement, J.A. and Mohanakrishnan, A.K. (2008) Synthesis and Characterization of Benzannelated Thienyl Oligomers. European European Journal of Organic Chemistry, 22, 3798-3810. https://doi.org/10.1002/ejoc.200800244

[16] Jung, Y.K., Kim, H., Park, J.H., Lee, J., Lee, S.K., Lee, Y.S. and Shim, H.K. (2008) Alternating Fluorene Copolymers Containing Isothianaphthene Derivatives: A Study of Their Aggregation Properties and Small Band Gap. Journal of Polymer Science Part A: Polymer Chemistry, 46, 3573-3590. https://doi.org/10.1002/pola.22696

[17] Willinger, K., Fischer, K., Kisselev, R. and Thelakkat, M. (2009) Synthesis, Spectral, Electrochemical and Photovoltaic Properties of Novel Heteroleptic Polypyridyl Ruthenium (II) Donor-Antenna Dyes. Journal of Materials Chemistry, 19, 5364-5376. https://doi.org/10.1039/b901988j

[18] Meng, H. and Wudl, F. (2001) A Robust Low Band Gap Processable n-type Conducting Polymer Based on Poly(Isothianaphthene). Macromolecules, 34, 1810-1816. https://doi.org/10.1021/ma001689v

[19] Sapp, S.A., Sotzing, G.A. and Reynolds, J.R. (1998) High Contrast Ratio and FastSwitching Dual Polymer Electrochromic Devices. Chemistry of Materials, 10, 2101 2108. https://doi.org/10.1021/cm9801237

[20] Kobayashi, M., Colaneri, N., Boysel, M., Wudl, F. and Heeger, A.J. (1985) The Electronic and Electrochemical Properties of Poly(Isothianaphthene). The Journal of Chemical Physics, 82, 5717-5723. https://doi.org/10.1063/1.448559

[21] Werbowyj, R.S. and Gray, D.G. (1976) Liquid Crystalline Structure in Aqueous HydroxyPropyl Cellulose Solutions. Molecular Crystals and Liquid Crystals, 34, $97-$ 103. https://doi.org/10.1080/15421407608083894

[22] Werbowyj, R.S. and Gray, D.G. (1984) Optical Properties of Hydroxypropyl Cellulose Liquid Crystals. I. Cholesteric Pitch and Polymer Concentration. Macromolecules, 17, 1512-1520. https://doi.org/10.1021/ma00138a016

[23] Bhadani, S.N. and Gray, D.G. (1983) Cellulose-Based Liquid Crystalline Polymers; Esters of (Hydroxypropyl) Cellulose. Molecular Crystals and Liquid Crystals, 99, 29-38. https://doi.org/10.1080/00268948308072026 
[24] Guido, S. (1995) Phase Behavior of Aqueous Solutions of Hydroxypropyl Cellulose. Macromolecules, 28, 4530-4539. https://doi.org/10.1021/ma00117a023

[25] Emam, H.E. and Ahmed, H.B. (2016) Polysaccharides Templates for Assembly of Nanosilver. Carbohydrate Polymers, 135, 300-307.

https://doi.org/10.1016/j.carbpol.2015.08.095

[26] Fernandes, S.N., Aguirre, L.E., Pontes, R.V., Canejo, J.P., Brogueira, P., Terentjev, E.M., and Godinho, M.H. (2016) Cellulose-Based Nanostructures for Photoresponsive Surfaces. Cellulose, 23, 465-476. https://doi.org/10.1007/s10570-015-0815-8

[27] Khan, A., Abas, Z., Kim, H.S. and Kim, J. (2016) Recent Progress on CelluloseBased Electro-Active Paper, Its Hybrid Nanocomposites and Applications. Sensors, 16, 1172. https://doi.org/10.3390/s16081172

Submit or recommend next manuscript to SCIRP and we will provide best service for you:

Accepting pre-submission inquiries through Email, Facebook, LinkedIn, Twitter, etc. A wide selection of journals (inclusive of 9 subjects, more than 200 journals)

Providing 24-hour high-quality service

User-friendly online submission system

Fair and swift peer-review system

Efficient typesetting and proofreading procedure

Display of the result of downloads and visits, as well as the number of cited articles Maximum dissemination of your research work

Submit your manuscript at: http://papersubmission.scirp.org/

Or contact msce@scirp.org 